\title{
Reproductive outcomes in women with hypogonadotrophic hypogonadism, a case series study
}

\author{
Ahmed Elsayed Abdelaal', Mohamed Atef Behery ${ }^{1 *}$ (D) and Ahmed Farouk Abdelkawi ${ }^{2}$
}

\begin{abstract}
Background: Hypogonadotropic hypogonadism $(\mathrm{HH})$ is a rare condition in which there is gonadal hypofunction due to absence of gonadotropin drive. In this condition, there are very low serum levels of gonadotropins. Pituitary gland may itself have some disease or disorder, or there may be loss of gonadotropin-releasing hormone (GnRH) pulses from the hypothalamus. The pharmacological interventions in $\mathrm{HH}$ women formed the basis for superovulation strategies for assisted reproduction techniques (ART) with a special reference to the role of LH and its impact on oocyte and embryo quality.

Results: The medians \pm inter quartile ranges for number of oocytes retrieved, number of MIl oocytes, and number of embryos transferred were $5 \pm 7,4 \pm 3$, and $3 \pm 1$ respectively. The pregnancy rate was $31.5 \%$ for this group of patients. The live birth rate and miscarriage rate were $21 \%$ and $11.5 \%$ respectively.

Conclusion: The reproductive outcomes of patients of hypogonadotrophic hypogonadism are reasonable after ICSI and clinical trials are recommended to corroborate this concern.
\end{abstract}

Keywords: Hypogonadotrophic, Hypogonadism, Reproduction, ICSI, Outcome, Pregnancy rate

\section{Background}

Gonadotropin-releasing hormone $(\mathrm{GnRH})$ acts via the $\mathrm{GnRH}$ receptor, which is expressed on gonadotropic cells in the anterior pituitary gland. This action regulates both synthesis and release of gonadotropins such as luteinizing hormone $(\mathrm{LH})$ and follicle-stimulating hormone (FSH), which control gonadal maturation and adult reproductive physiology via the hypothalamic-pituitary-gonadal (HPG) axis [1].

Hypogonadotrophic hypogonadism $(\mathrm{HH})$ diagnosis was based on clinical history of primary or secondary amenorrhea, negative progestin challenge, serum levels of both $\mathrm{FSH}$ and luteinizing hormone $(\mathrm{LH})<5 \mathrm{IU} / \mathrm{L}$, accompanied by serum estradiol levels below $20 \mathrm{pg} / \mathrm{mL}$ [2].

\footnotetext{
* Correspondence: abehery133@icloud.com

${ }^{1}$ Reproduction Unit, The International Islamic Institute for Population Studies and Research, Al Azhar University, Cairo, Egypt

Full list of author information is available at the end of the article
}

Hypogonadotropic hypogonadism ( $\mathrm{HH}$ ) has multiple etiologies and is characterized by ovulation disorders, low levels of endogenous gonadotropins, and estrogen deficiency caused by hypothalamic pituitary failure [3].

Congenital hypogonadotropic hypogonadism $(\mathrm{CHH})$ is caused by deficient production, secretion, or action of $\mathrm{GnRH}$, a key neuropeptide that orchestrates mammalian reproduction [4].

The congenital form is known as idiopathic $\mathrm{HH}$, and accounting for approximately $40-60 \%$ of all cases [5]. When the condition is acquired, it is usually characterized by functional amenorrhea with low estrogen levels in women with a low body mass index (BMI) [6].

$\mathrm{CHH}$ can present solely as congenital $\mathrm{GnRH}$ deficiency or be associated with other developmental anomalies such as cleft lip or palate, dental agenesis, ear anomalies, congenital hearing impairment, renal agenesis, bimanual synkinesis, or skeletal anomalies $[7,8]$.

\section{Springer Open}

(c) The Author(s). 2021 Open Access This article is licensed under a Creative Commons Attribution 4.0 International License, which permits use, sharing, adaptation, distribution and reproduction in any medium or format, as long as you give appropriate credit to the original author(s) and the source, provide a link to the Creative Commons licence, and indicate if changes were made. The images or other third party material in this article are included in the article's Creative Commons licence, unless indicated otherwise in a credit line to the material. If material is not included in the article's Creative Commons licence and your intended use is not permitted by statutory regulation or exceeds the permitted use, you will need to obtain permission directly from the copyright holder. To view a copy of this licence, visit http://creativecommons.org/licenses/by/4.0/. 
Puberty can be induced by oral or preferably transdermal estradiol administration in girls. Estrogen treatment increases uterine size and combined estrogen and progestin therapy induces monthly withdrawal bleeding but does not induce ovulation. For fertility, gonadotropins or GnRH therapies are necessary and effective [9].

$\mathrm{HH}$ patients will likely require either hormonal replacement therapy to regularize their cycles or ART depending on their reproductive desire. Low complexity techniques can be offered, but many women will need in vitro fertilization (IVF) [10].

There is limited evidence for ovarian response and reproductive outcomes of $\mathrm{HH}$ patients who undergo IVF. Some studies have reported similar overall IVF performance in this group of patients compared to other infertility causes [11].

Being a rare condition, there are a limited number of studies evaluating the reproductive capacity and infertility treatment outcome of women with $\mathrm{HH}$.

Because of this limitation, this study was conducted, aimed to evaluate the reproductive outcome of this group of patients and to help clinicians to select the proper management for these patients.

\section{Methods}

This is a case series study including 19 patients who attended the assisted reproduction unit, Al-Azhar University, Cairo, Egypt, in the period from May 2016 to March 2019 with confirmed diagnosis of congenital hypogonadotrophic hypogonadism and planned for ICSI. $\mathrm{HH}$ diagnosis was based on a clinical history of primary or secondary amenorrhea, ultrasound picture of small size ovaries, negative progestin challenge, and serum levels of both FSH and luteinizing hormone $(\mathrm{LH})<1$ IU/L [5], accompanied by serum estradiol levels below $20 \mathrm{pg} / \mathrm{mL}$ [3]. Considering that the patients included in this study had no previous normal cycles.

All patients were received combined oral contraceptives containing estrogen and progesterone (Gynera, Bayer Pharma AG, Berlin, Germany), 2 months before stimulation to help endometrial regeneration and regulation of the cycle. Ovulation induction was started at the second day of bleeding by 150-225 IU of human menopausal gonadotrophin (hMG, Menogon, 75 IU, Ferring Pharmaceuticals). Follicular tracking was continued until scanning showed at least 3 mature follicles. Triggering was performed by human chorionic gonadotrophin (Pregnyl 10000 IU, Organon, Kloosterstraat, Netherlands) administered intramuscular followed by ovum pick up $36 \mathrm{~h}$ later. Embryo transfer was done at day 2-5 after pick up. Luteal phase support by vaginal progesterone gel (Crinone gel $8 \%$, Merck-Serono, Germany) was given for 2 weeks until pregnancy was confirmed, then it was continued during the first trimester. Pregnancy was followed until delivery, where miscarriage rate and live birth rate were estimated. The primary outcome was the pregnancy rate. The secondary outcome was the live birth rate and miscarriage rate.

\section{Statistical analysis}

Statistical analysis was performed using Microsoft Excel 2013(Microsoft Company, USA) and soft package of statistical analysis (SPSS version 22, IBM Company, Chicago ,USA). The Normality of data was tested using normality tests (Kolomogrov, Semirenov test of normality). The data was presented by median and inter-quartile range (IQR) for quantitative data. Frequency and percentages were used for presentation of qualitative data. Man Whitney test was used for the comparison between qualitative data and Fisher exact or -square tests were used for the comparison between categorical data.

\section{Results}

Medians $\pm \mathrm{IQRs}$ for age, BMI, total dose of stimulation, and duration of stimulation were $29 \pm 6,30.9 \pm 5,5250 \pm$ 2100 , and $15 \pm 3$ respectively (Table 1 ). The outcomes of ICSI for the 19 patients were (median \pm IQR were 1826 $\pm 2473,10 \pm 1,5 \pm 7,4 \pm 3,1 \pm 1,0 \pm 2,3 \pm 1,2 \pm 1,0 \pm 0$ ) for E2 and endometrial thickness at the day of triggering, oocyte number, MII oocyte, MI oocytes, germinal vesicles, embryos number, grade A and B embryos respectively. Four cases got pregnant with the pregnancy rate of $31.6 \%$. Four cases were delivered four term babies with live birth rate $4 / 19$ (21\%) while two cases showed first trimestric abortion with miscarriage rate of $10.5 \%$ (Table 2 and Fig. 1).

\section{Discussion}

The median number of oocytes retrieved in the current study was four. The lower number of oocytes retrieved may be explained by the study of Bry-Gauillard et al. [12], who assessed the number of antral follicles of 39 patients with isolated $\mathrm{HH}$ and observed a significantly lower AFC compared to 41 healthy controls. Interestingly, persistent FSH deficit in isolated $\mathrm{HH}$ can lead to diminished ovarian size and reduced AFC and in turn the number of oocytes retrieved [13].

Despite the similarity of results between this study and the study by Bry-Gauillard et al., the patients included were the patients with isolated $\mathrm{HH}$ while the patients in our study were the patients with congenital $\mathrm{HH}$.

Another study with $\mathrm{HH}$ patients due to multiple etiologies also reported lower AFC [2]. However, many authors reported normal follicular count, but these results could be explained by the type of patients in the studies where women with small-sized ovaries who showed multi follicular or normal-sized ovaries as in cases of functional hypogonadism were included [9]. 
Table 1 The basal characteristics of the studied patients

\begin{tabular}{llc} 
Variable & Median \pm IQR*(Minimum.-Maximum.) & Mean \pm SD \\
\hline Age (years) & $29 \pm 6(23-40)$ & $28.89 \pm 4.126$ \\
Body Mass Index(BMI) & $30.9 \pm 5(25-38)$ & $31.27 \pm 3.357$ \\
Total dose of stimulation & $5250 \pm 2100(2700-8100)$ & $5080 \pm 1527$ \\
Duration of stimulation & $15 \pm 3(11-18)$ & $14.58 \pm 2$
\end{tabular}

*As non-normal data distribution, the values were estimated by median and inter-quartile range (IQR)

Some studies have evaluated the efficiency of different protocols and reproductive outcomes in this group of patients $[14,15]$. They generally showed good response and high pregnancy rates, even though higher gonadotropin doses are usually required [16-18]. Our results prove these findings in view of good pregnancy rate (31\%) and relatively high dose of stimulation (median \pm
IQR, $5250 \pm 2100$ ) but low oocytes number (median \pm IQR, 5 \pm 7 ).

Because of the low levels of FSH and LH, downregulation by either gonadotrophins-releasing hormone agonist $(\mathrm{GnRH}$ a) or antagonist ( $\mathrm{GnRH}$ ant) was not required based on the results claim from detrimental effect of the pituitary suppression in women with congenital $\mathrm{HH}$, on

Table 2 The outcomes after stimulation in the studied patients

\begin{tabular}{|c|c|c|}
\hline Variable & Median \pm IQR*(Minimum.-Maximum.) & Mean \pm SD \\
\hline $\begin{array}{l}\text { - } \\
\text { E2 at day of } \\
\text { triggering }\end{array}$ & $1826 \pm 2473(789-5732)$ & $2495 \pm 1471$ \\
\hline $\begin{array}{l}\text { Endometrial } \\
\text { thickness at the } \\
\text { day of triggering }\end{array}$ & $10 \pm 1(8-14)$ & $10 \pm 1.5$ \\
\hline - Oocyte number & $5 \pm 7(1-13)$ & $6.3 \pm 3.4$ \\
\hline - MII Oocytes & $4 \pm 3(1-10)$ & $4 \pm 2.4$ \\
\hline - MI Oocytes & $1 \pm 1(0-4)$ & $1.5 \pm 0.9$ \\
\hline - $\quad \mathrm{GVs}$ & $0 \pm 2(0-3)$ & $0.79 \pm 1.2$ \\
\hline - $\quad$ Embryos number & $3 \pm 1(1-3)$ & $2.5 \pm 0.7$ \\
\hline - Grade B embryos & $2 \pm 1(0-3)$ & $2.2 \pm 0.84$ \\
\hline & $0 \pm 0(0-1)$ & $0.21 \pm 0.41$ \\
\hline - Pregnancy rate & \multicolumn{2}{|l|}{$31.5 \%(6 / 19)$} \\
\hline $\begin{array}{l}\text { - Miscarriage rate } \\
\text { - Live birth rate }\end{array}$ & \multicolumn{2}{|l|}{$10.5 \%(2 / 19)$} \\
\hline & \multicolumn{2}{|l|}{$21 \%(4 / 19)$} \\
\hline
\end{tabular}




\section{PREGNANCY RATE}

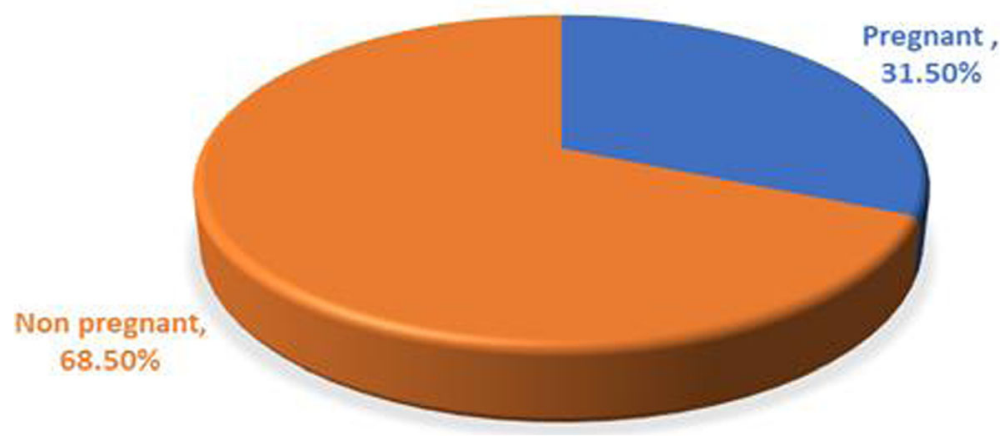

Fig. 1 Pregnancy rate in the studied group

implantation and live birth rates [19]. Unlike our study, the previous results were applied to the patients with congenital and functional hypogonadism.

In all patients, we started with a stimulation dose of 150-225 IU. However, some studies had recommended to start with a dose not exceeding 75 IU and step up after 5 to 7 days [9]. This conflict may be resolved by the differences in patients selected.

Stimulation can be started on any day during amenorrhea or after an $\mathrm{E}+\mathrm{P}$ withdrawal bleeding. Two to three months priming with sequential $\mathrm{E}+\mathrm{P}$ treatment may improve response.

In a study by Yaldrim et al., they reported that patients with $\mathrm{HH}$ should be given oral contraceptives for at least 2 months before controlled ovarian hyper stimulation treatment to change the hypo estrogenic environment and to improve endometrial development [20].

In some studies, this priming is not required. A novel concept of LH priming has been suggested. Pretreatment with $300 \mathrm{IU}$ SC of $\mathrm{rLH}$ for 7 days immediately preceding the rFSH significantly decreased the requirement of FSH [21].

In a review article of several studies published from 1966 to 1984, the pregnancy rate varied from 16 to $78 \%$ in different studies [22]. This coincides with our results (pregnancy rate $31 \%$ ).

The live birth rate (LBR) in the current study was $21 \%$ which is approximately around the rate reported in the clinical trial conducted by Firouzeh et al. [23], where they compared the live birth rate after ICSI in 81 cases of $\mathrm{HH}$ with 88 cases with tubal factor infertility. However, no significant difference was detected.

In the current study, hMG was used for stimulation. However rFSH can be used only if combined with $\mathrm{rLH}$ as evidenced by many studies [24-26]. Interestingly,in the study by Kumback and Kahraman, they reported simillar results if any of both stimulations was used [15].
Descriptive studies showed that the results of ART in $\mathrm{HH}$ patients treated with HMG were comparable to those in women with tubal factor infertility and unexplained infertility $[16,20]$.

In addition, earlier meta-analysis showed that when a $\mathrm{GnRH}$ a long protocol was used, hMG was superior to using only $\mathrm{rFSH}$ in IVF/intra-cytoplasmic sperm injection (ICSI) treatment $[27,28]$.

There have been several studies to increase the success rate with FSH and $\mathrm{LH}$. As a result of these studies, it seems that a combined stimulation with FSH and LH is the best treatment option. However, it was concluded that the FSH/LH ratio should be $2 / 1$ in the first half of the stimulation cycle, and $1 / 2$ in the second half $[14,29,30]$.

In patients with congenital $\mathrm{HH}$, there is a lack of gonadotropin throughout the life, so there may be adverse effects of long-term LH deficiency on ovarian response and embryo implantation.

Due to the very low incidence of $\mathrm{HH}$, many studies have been done to evaluate the influence of $\mathrm{LH}$ on follicular growth and oocyte quality in downregulated patients undergoing an IVF procedure [31, 32].

Several clinical studies have shown that a low concentration of LH leads to reduced ovarian estradiol biosynthesis because of the reduced thecal production of androgen precursors and consequently causes higher implantation failure and early pregnancy loss rates [32-34].

In contrary to this proposal, Yaldrim et al. compared HH patient ART outcomes with mild and moderate male factor infertility patients. They found that the response to fertility treatment in these patients was at least as good as in the control group [20].

In another prospective study by Yalmaz et al. [11], they reported that the duration of stimulation was longer and total gonadotropin dose was higher in the $\mathrm{HH}$ group. However, there were no differences in human chorionic gonadotropin (hCG) day estradiol levels, endometrial 
thickness on hCG day, total oocyte number retrieved, MII oocyte number, or pregnancy rate.

To obtain acceptable rates of pregnancy with minimal side effects, determining the ovarian response before treatment is crucial. However, predicting the ovarian response to treatment of patients with $\mathrm{HH}$ is difficult because the lower level of gonadotropin, small ovaries, and amenorrhea renders ovarian reserve tests unreliable.

Sonmezer et al. [35] found that the level of antiMullarian hormone $(\mathrm{AMH})$ is correlated with ovarian response in patients with $\mathrm{HH}$. Unfortunately, in this study, AMH was not done for all patients, firstly, because of the cost; secondly, because it is not a routine for the diagnosis of patients with $\mathrm{HH}$.

Understanding of the molecular genetics of $\mathrm{CHH}$ is mandatory to know about the pathophysiology of this syndrome and to improve the treatment strategy.

Although patients with $\mathrm{HH}$ have a long-term estrogen deficiency, their response to controlled ovarian hyper stimulation treatment is like normal women as proved by previous studies and potentially by the current study. However, the $\mathrm{HH}$ group is heterogeneous and estimating their ovarian reserve is not always possible before treatment.

Several strengths are recognized in the design of this study. First, the prospective nature of the study made it more likely that the data collected would be complete. Also, consecutive patients were included in this series. Selection bias was limited because all patients who started stimulation protocol in the observed period were included in the study. The authors justly did not overstep the goal of a case series, as their goal was to present their results with conventional stimulation protocol. Because patients were followed until the end of treatment, this study is complete with regard to the report for potential complications associated with the treatment.

However, keeping the methodological limitations of a case series in mind, we cannot apply this conclusion to clinical practice before more evidence is obtained from randomized trials. Nevertheless, with good design and conduction, this study can be a sensible alternative to studies with higher levels of evidence, with the additional advantage of saving a lot of time and money.

\section{Conclusion}

The results of this study were considered reasonable if compared to the reproductive outcomes of patients with other infertility causes like tubal factor. So, we can conclude that there are no precautions that should be taken, or adverse effects expected, like cycle cancelation or empty follicle syndrome, when starting ovarian stimulation during ICSI cycles in patients of hypo gonadotrophic hypogonadism. Clinical trials are recommended to corroborate this concern.

\section{Abbreviations}

CHH: Congenital hypogonadotrophic hypogonadism; GnRH: Gonadotrophin releasing hormone; AMH: Anti-Mullerian hormone; HCG: Human chorionic gonadotrophin; ICSI: Intracytoplasmic sperm injection

\section{Acknowledgements}

The authors introduced many thanks to embryology units' staff for their support and valuable data provided until finishing this work.

\section{Authors' contributions}

AA: data collection and review writing. MA: statistical analysis, review writing, AF: paper revision and editing. All authors have read and approved the manuscript.

\section{Funding}

No funding was introduced either by individuals or organizations.

Availability of data and materials

Data is available upon request.

\section{Declarations}

Ethics approval and consent to participate

the study had been approved by university medical ethical committee (registry number, GYN._305 Med.Research._0000305) and all patients in the study had been signed for a written consent before procedure.

\section{Consent for publication}

All authors agreed for publication upon acceptance of the paper.

\section{Competing interests}

The authors did not report any conflict of interest.

\section{Author details}

${ }^{1}$ Reproduction Unit, The International Islamic Institute for Population Studies and Research, Al Azhar University, Cairo, Egypt. ²Department of Obstetrics and Gynecology, Faculty of Medicine, Assiut University, Assiut, Egypt.

Received: 2 May 2020 Accepted: 25 March 2021

Published online: 19 April 2021

\section{References}

1. Handbook of biologically active peptides (2013); (Second Edition); 31,32.

2. Jiang S, Kuang Y (2018) The effects of low-dose human chorionic gonadotropin combined with human menopausal gonadotropin protocol on women with hypogonadotropic hypogonadism undergoing ovarian stimulation for in vitro fertilization. Clin Endocrinol 88(1):77-87. https://doi. org/10.1111/cen.13481

3. Boehm U, Bouloux P-M, Dattani MT, de Roux N, Dodé C, Dunkel L et al (2015) European consensus statement on congenital hypogonadotropic hypogonadism — pathogenesis, diagnosis and treatment. Nat Rev Endocrinol. 11(9):547-564. https://doi.org/10.1038/nrendo.2015.112

4. Bianco SD, Kaiser UB (2009) The genetic and molecular basis of idiopathic hypogonadotropic hypogonadism. Nat. Rev. Endocrinol. 5(10):569-576. https://doi.org/10.1038/nrendo.2009.177

5. Silveira LFG, Latronico AC (2013) Approach to the patient with hypogonadotropic hypogonadism. J Clin Endocrinol Metab 98(5):17811788. https://doi.org/10.1210/jc.2012-3550

6. Jonard $S$, Pigny $P$, Jacquesson $L$, Demerle-Roux $C$, Robert $Y$, Dewailly $D$ (2005) The ovarian markers of the FSH insufficiency in functional hypothalamic amenorrhea. Hum Reprod. 20(1):101-107. https://doi.org/10.1 093/humrep/deh560

7. Schwanzel-Fukuda M, Bick D, Pfaff DW (1989) Luteinizing hormone-releasing hormone (LHRH)-expressing cells do not migrate normally in an inherited hypogonadal (Kallmann) syndrome. Brain Res. Mol. Brain Res. 6(4):311-326. https://doi.org/10.1016/0169-328X(89)90076-4

8. Teixeira $L$ (2010) Defective migration of neuroendocrine $\mathrm{GnRH}$ cells in human arrhinencephalic conditions. J. Clin. Invest. 120(10):3668-3672. https://doi.org/10.1172/JCl43699

9. -Gustavo N. Cecchino1,2,3 \& Guillermo M. Canillas3 \& María Cruz3 \& Juan A. García-Velasco (2019); Impact of hypogonadotropic hypogonadism on 
ovarian reserve and response Journal of Assisted Reproduction and Genetics ;36:2379-2384

10. Gao Y, Yu B, Mao J, Wang X, Nie M, Wu X (2018) Assisted reproductive techniques with congenital hypogonadotropic hypogonadism patients: a systematic review and meta-analysis. BMC Endocr Disord 18:85

11. Yilmaz S, Ozgu-Erdinc AS, Yumusak O, Kahyaoglu S, Seckin B, Yilmaz N (2015) The reproductive outcome of women with hypogonadotropic hypogonadism undergoing in vitro fertilization. Syst Biol Reprod Med. 61(4): 228-232. https://doi.org/10.3109/19396368.2015.1037936

12. Bry-Gauillard H, Larrat-Ledoux F, Levaillant J-M, Massin N, Maione L, Beau I, Binart N, Chanson P, Brailly-Tabard S, Hall JE, Young J (2017) Anti-Müllerian hormone and ovarian morphology in women with isolated hypogonadotropich ypogonadism/Kallmann syndrome: effects of recombinant human. FSH. J Clin Endocrinol Metab. 102:1102-1111. https:// doi.org/10.1210/jc.2016-3799

13. Tsilchorozidou T, Conway GS (2004) Uterus size and ovarian morphology in women with isolated growth hormone deficiency, hypogonadotrophic hypogonadism and hypopituitarism. Clin Endocrinol. 61(5):567-572. https:// doi.org/10.1111/j.1365-2265.2004.02126.x

14. Shoham Z, Smith H, Yeko T, O'Brien F, Hemsey G, O'Dea L (2008) Recombinant LH (lutropin alfa) for the treatment of hypogonadotrophic women with profound LH deficiency: a randomized, double-blind,placebocontrolled,proof-of-efficacystudy. Clin Endocrinol. 69:471-478. https://doi. org/10.1111/j.1365-2265.2008.03299.x

15. Kumbak B, Kahraman S (2006) Women with hypogonadotropic hypogonadism: cycle characteristics and results of assisted reproductive techniques. Acta Obstet Gynecol Scand. 85(12):1453-1457. https://doi.org/1 0.1080/00016340600839619

16. Ulug U, Ben-Shlomo I, Tosun S, Erden HF, Akman MA, Bahceci M (2005) The reproductive performance of women with hypogonadotropic hypogonadism in an in vitro fertilization and embryo transfer program. J Assist Reprod Genet. 22(4):167-171. https://doi.org/10.1007/s10815-005-4914-6

17. Lewit $\mathrm{N}$, Kol S (2000) The low responder female IVF patient with hypogonadotropic hypogonadism: do not give up! Fertil Steril. 74(2):401402. https://doi.org/10.1016/S0015-0282(00)00599-9

18. Balasch J, Miró F, Burzaco I, Casamitjana R, Civico S, Ballescá JL et al (1995) The role of luteinizing hormone in human follicledevelopment and oocyte fertility: evidence from in-vitro fertilization in a woman with long-standing hypogonadotrophic hypogonadism and using recombinant human follicle stimulating hormone. Hum Reprod. 10:1678-1683

19. -Mumusoglu S, Ata B, Turan V, Demir B, Kahyaoglu I, Aslan K, et al. (2017); Does pituitary suppression affect live birth rate in women with congenital hypogonadotrophic hypogonadism undergoing intracytoplasmic sperm injection? A multicenter cohort study. Gynecol Endocrinol.; 33:728.

20. Yildirim G, Ficicioglu C, Attar R, Akcin O, Tecellioglu N (2010) Comparision of reproductive outcome of the women with hypogonadotropic hypogonadism and tubal factor infertility. Clin Exp Obstet Gynecol. 37:120-122

21. Kaufmann R, Dunn R, Vaughn T, Hughes G, O'Brien F, Hemsey G et al (2007) Recombinant human luteinizing hormone, lutropin alfa, for the induction of follicular development and pregnancy in profoundly gonadotrophindeficient women. ClinEndocrinol. 64:563-569

22. Filicori M, Cognigni GE, Pocognoli P, Tabarelli C, Ferlini F, Perri T, Parmegiani $L$ (2003) Comparison of controlled ovarian stimulation with human menopausal gonadotropin or recombinant follicle-stimulating hormone. Fertil Steril. 80(2):390-397. https://doi.org/10.1016/S0015-0282(03)00594-6

23. Firouzeh G, Arezoo A, Narges B, Lankaran S, Ensieh S, Tehrani N (2013) Assisted reproductive technique outcomes in hypogonadotropic hypogonadism women May. Ann Saudi Med 33(3):235-240

24. Berger MJ, Taymor ML (1971) The role of luteinizing hormone in human follicular maturation and function. Am J Obstet Gynecol 111(5):708-710. https://doi.org/10.1016/0002-9378(71)90978-1

25. Fox R, Ekeroma A, Wardle P (1997) Ovarian response to purified FSH in infertile women with long-standing hypogonadotrophic hypogonadism. Aust N Z J Obstet Gynaecol 37(1):92-94. https://doi.org/10.1111/j.1479-82 8X.1997.tb02226.x

26. Schoot DC, Harlin J, Shoham Z, Mannaerts BM, Lahlou N, Bouchard P et al (1994) Recombinant human follicle stimulating hormone and ovarian response in gonadotrophin-deficient women. Hum Reprod 9(7):1237-1242. https://doi.org/10.1093/oxfordjournals.humrep.a138685
27. Jee BC, Suh CS, Kim YB, Kim SH, Moon SY (2010) Clinical efficiacy of highly purified hMG versus recombinant FSH in IVF/ICSI. Gynecol Obstet Invest. 70(2):132-137. https://doi.org/10.1159/000308458

28. Van Wely M, Westergaard LG, Bossuyt PM, Van der Veen F (2003) Human menopausal gonadotropin versus recombinant follicle stimulation hormone for ovarian stimulation in assisted reproductive cycles. Cochrane Database Syst Rev 2:CD003973

29. Burgues S, Spanish Collaborative Group on Female Hypogonadotropic Hypogonadism (2001) The effectiveness and safety of recombinant human LH to support follicular development induced by recombinant human FSH in WHO group I anovulation: evidence from a multicentre study in Spain. Hum Reprod 16:2525-2532

30. Chappel SC, Howles C (1991) Reevaluation of the roles of luteinizing hormone and follicle-stimulating hormone in the ovulatory process. Hum Reprod 6(9): 1206-1212. https://doi.org/10.1093/oxfordjournals.humrep.a137513

31. Fleming R, Lloyd F, Herbert M, Fenwick J, Griffiths T, Murdoch A (1998) (1998) Effects of profound suppression of luteinizing hormone during ovarian stimulation on follicular activity, oocyte and embryo function in cycles stimulated. Hum Reprod. 13(7):1788-1792. https://doi.org/10.1093/ humrep/13.7.1788

32. Westergaard LG, Laursen SB, Andersen CY (2000) Increased risk of early pregnancy loss by profound suppression of luteinizing hormone during ovarian stimulation in normogonadotrophic women undergoing assisted reproduction. Hum Reprod 15(5):1003-1008. https://doi.org/10.1093/ humrep/15.5.1003

33. Balasch J, Vidal E, Penarrubia J, Casamitjana R, Carmona F, Creus M et al (2001) Suppression of LH during ovarian stimulation: analyzing threshold values and effects on ovarian response and the outcome of assisted reproduction in down-regulated women stimulated with recombinant FSH. Hum Reprod 16(8):1636-1643. https://doi.org/10.1093/humrep/16.8.1636

34. Lahoud R, Al-Jefout M, Tyler J, Ryan J, Driscoll G (2006) A relative reduction in mid-follicular LH concentrations during GnRH agonist IVF/ICSI cycles leads to lower live birth rates. Hum Reprod 21(10):2645-2649. https://doi. org/10.1093/humrep/del219

35. Sonmezer M, O "zmen, B., Atabekoglu, C.S., Pabuccu, E.G., Ozkavukcu, S., Berker, B., et al. (2012) Serum anti-Mullerian hormone levels correlate with ovarian response in idiopathic hypogonadotropic hypogonadism. J Assist Reprod Genet 29(7):597-602. https://doi.org/10.1007/s10815-012-9759-1

\section{Publisher's Note}

Springer Nature remains neutral with regard to jurisdictional claims in published maps and institutional affiliations.

\section{Submit your manuscript to a SpringerOpen ${ }^{\circ}$ journal and benefit from:}

- Convenient online submission

- Rigorous peer review

- Open access: articles freely available online

High visibility within the field

- Retaining the copyright to your article

Submit your next manuscript at $>$ springeropen.com 